Conclusion: The study highlighted that a reduced DLCO in lung function test is associated with a lung involvement in IRD. DLCO represented a potential screening parameter for lung manifestation in IRD. Especially patients with suspected vasculitis should receive an additional chest $\mathrm{x}$-ray. Based on the high sensitivity of DLCO in combination with chest x-ray or HR-CT for the detection of ILD in IRD, all patients with a reduced DLCO $(<80 \%)$ should obtained an imaging of the lung. Disclosure of Interests: None declared

DOI: 10.1136/annrheumdis-2021-eular.3119

\section{AB0797 THE ROLE OF ULTRASOUND CRITERIA IN ASSESSING PAIN SYNDROME IN THE KNEE JOINT IN PATIENTS WITH RHEUMATOID ARTHRITIS AND OSTEOARTHRITIS}

N. Aleksandrova ${ }^{1}, A$. Aleksandrov ${ }^{1,2} .{ }^{1}$ Federal State Budgetary Institution «Research Institute of Clinical and Experimental Rheumatology named after A.B. Zborovsky», Department of Functional Research Method, Volgograd, Russian Federation; ${ }^{2}$ Volgograd State Medical University, Department of Hospital Therapy, Volgograd, Russian Federation

Background: Pain syndrome and pathological changes in the synovium detected by ultrasound can be early signs of various diseases of the joints [1].

Objectives: the use of ultrasound criteria for changes in the synovial membrane of the joint cavity to assess the severity of pain in patients with rheumatoid arthritis (RA) and osteoarthritis (OA).

Methods: The study included 36 patients with RA (32 women and 4 men aged 22 to 55 years old) and 38 patients with OA (30 women and 8 men aged 30 to 50 years old) with lesions of the knee joints. A visual analogue scale (VAS) was used to determine the severity of pain. The severity of pain in the knee when walking was at least $40 \mathrm{~mm}$ according to the VAS in all examined patients. Joint ultrasound examination was carried out according to the standard technique using a linear transducer with a frequency of $5-12 \mathrm{MHz}$ on an Accuvix V10 ultrasound diagnostic system (Samsung Medison, South Korea). The evaluation of ultrasound changes in the upper inversion of a knee joint was carried out according to the following criteria: the severity of intra-articular effusion (1), synovial proliferation (2), local vascularization of the synovial membrane using power Doppler (3) (Table 1)

Table 1. Parameters of ultrasound criteria for assessing changes in the synovial membrane of the joint cavity

\begin{tabular}{ll}
\hline Normal indicators & 1 - width of the suprapatellar turn is $6 \mathrm{~mm}$ \\
& 2 - thickness of the synovial membrane is $3 \mathrm{~mm}$ (from the anterior \\
approach) & 3 - lack of vascularization loci \\
& 1 - delamination of the suprapatellar curl leaves from 7 to $9 \mathrm{~mm}$ \\
& 2 - thickness of the synovial membrane $3.1-4.5 \mathrm{~mm}$ \\
Minimum changes & 3 - appearance of single loci of vascularization $(1-2$ in the Doppler field) \\
Moderate changes & 1 - delamination of the leaves of the suprapatellar twist $10-14 \mathrm{~mm}$ \\
& 2 - thickness of the synovial membrane is $4.6-6.4 \mathrm{~mm}$ \\
Severe changes & 3 - appearance of moderate $(>5)$ vascularization loci \\
& 1 - delamination of suprapatellar folds of more than $15 \mathrm{~mm}$ \\
& 2 - thickness of the synovial membrane is more than $6.5 \mathrm{~mm}$ \\
& 3 - multiple foci of vascularization $(>5$, merging in places)
\end{tabular}

Results: Correlations of various severity were found between pain indices according to VAS and the thickness of the synovial membrane of the knee joint $(r=0.33, p=0.019)$ and the number of vascularization foci $\left(r_{S}=0.29, p=0.04\right)$ in RA patients, as well as between pain according to VAS and the severity of intra-articular effusion $(r=0.28, p<0.002)$ in patients with $O A$.

The patients were divided into three groups according to the severity of pain in the knee joint: group I - 41-59 mm (12 patients with OA and 9 patients with RA), group II - 60-79 mm (16 patients with OA and 12 patients with RA), group III - 80-100 mm on the VAS scale (10 patients with OA and 15 patients with RA). Group I was dominated by OA patients with minimal changes in intra-articular effusion and local vascularization of the synovial membrane, with moderate synovial proliferation (28.6\% of the total number of patients in the group). In group II patients with OA with moderate severity of intra-articular effusion and local vascularization (21.4\%) and patients with RA with moderate changes in the thickness of the synovium and local vascularization (25\%) were equally common. Group III was dominated by RA patients with severe synovial proliferation and moderate local vascularization $(28 \%)$, as well as patients with OA with moderate intra-articular effusion (20\%). Significant differences in the thickness of the synovium in patients with RA in the first and third groups were noted $(\mathrm{H}$-test $=5.9, \mathrm{p}=0.025)$.

Conclusion: The additional use of ultrasound criteria for changes observed in the synovial membrane of the joint cavity in patients with RA and OA can help predict pain in the knee joint. The manifestation of pain syndrome in patients with $\mathrm{OA}$ is most associated with the severity of synovitis in the joint, and in patients with RA - with the severity of synovial proliferation.

REFERENCES:

[1] Sarmanova A et al. Arthritis Res Ther. 2017;19(1):281
Disclosure of Interests: None declared

DOI: 10.1136/annrheumdis-2021-eular.3224

\section{AB0798 \\ IS THERE A REPRODUCIBILITY OF THE HISTOGRAM AND GRAY SCALE IN ECOEXTRUCTURAL DAMAGES IN RHEUMATOTOLOGICAL DISEASES?}

J. A. Mendonça ${ }^{1}$, I. Siste de Almeida Aoki ${ }^{1}$, C. C. Cavuto ${ }^{2}$, V. A. Leandro-Merhi ${ }^{3}$ J. L. B. D. Aquino ${ }^{3}$ on behalf of Postgraduate Program in Health Sciences, Pontifical Catholic University of Campinas. . ${ }^{1}$ Pontifical Catholic University of Campinas, Rheumatology/Postgraduate Program in Health Sciences, Campinas, Brazil; ${ }^{2}$ Pontifical Catholic University of Campinas, Rheumatology/ Scientific Initiation Program, Campinas, Brazil; ${ }^{3}$ Pontifical Catholic University of Campinas, Postgraduate Program in Health Sciences, Campinas, Brazil

Background: The gray scale (GS) in high resolution ultrasound is already well validated for use in rheumatological diseases, but the color map or the histogram, can be considered a new proposal, to better define and complement the echotextural damages detection ${ }^{1}$.

Objectives: To calculate the lesions area measures reproducibility index in arthropathies, between 3 blind evaluators and correlate these measures using the GS and the histogram.

Methods: Observational and retrospective study approved by the ethics committee of the Pontifical Catholic University of Campinas, with the opinion num ber: 1.526.307. A total of 29 patients have been assessed $(31 \%$ males and $69 \%$ females) on period 2014 to 2019 in Rheumatology service. A MyLab 50 -Esaote equipment was used with frequency transducer that ranged between 6.0 and 18.0 $\mathrm{MHz}, 10$ different area measures were performed from each recorded images previously, by the GS and the histogram. Statistical analysis: Spearman's correlation coefficients, Lin's concordance coefficient (CCC) and the intraclass correlation coefficient (ICC) and their respective 95\% confidence intervals, with the SPSS software package for Windows v. 17.0 (SPSS Inc., Chicago, IL, USA). Results: Average age $43.5 \pm 21.5$ years of age; with disease duration that var ied between $\leq 1$ month (48.3\%) and $\geq 36$ months $(24.1 \%)$; with the following diseases: juvenile idiopathic arthritis (17.24\%); osteoarthritis (13.79\%); psoriatic arthritis $(13.79 \%)$; undifferentiated spondyloarthritis $(3.44 \%)$; gout $(20.68 \%)$ rheumatoid arthritis (27.58\%) and reactive arthritis (3.44\%). A total of 840 measures of exudative $(27.58 \%)$, proliferative $(27.58 \%)$ and snowstorm appearance $(6.89 \%)$ synovitis were performed; femoral-condyle cartilage $(3.44 \%)$; synovial cyst $(3.44 \%)$; paratendinitis $(6.89 \%)$; calcification $(3.44 \%)$; nail enthesitis (3.44\%); tenosynovitis (6.89\%) and tophi (10.34\%) (Figure 1). The concordance correlation coefficient showed values closer to $1 ; p<0.001$, the intraclass correlation coefficients with excellent reproducibility (ICC $\geq 0.75$ ); $p<0.001$, always in relation to the three evaluators (Table 1) and the Spearman correlation between the GS and the histogram ranged from $r s=0.665$ to $r s=1,000 ; p<0.001$.

Conclusion: The histogram can be considered an image method to better identify echotextural damages.

\section{REFERENCES:}

[1] Mendonça J, Provenza J, Guissa V, et al AB1059 2D Histogram Ultrasound and 3D Ultrasound Correlation in Rheumatic Diseases Annals of the Rheumatic Diseases 2015; 74:1253-1254.

Table 1. Concordance Correlation Coefficient (CCC) and Intraclass Correlation Coefficient (ICC):

\begin{tabular}{|c|c|c|c|c|}
\hline Evaluators & $\begin{array}{c}\text { GS - CCC } \\
\text { (IC 95\%) }\end{array}$ & p-valor & $\begin{array}{c}\text { Histogram (IC } \\
95 \%)\end{array}$ & p-valor \\
\hline 1 e 2 & $\begin{array}{c}0,998 \\
(0,994-0,999)\end{array}$ & $<0,001$ & $\begin{array}{c}0,999 \\
(0,995-1,000)\end{array}$ & $<0,001$ \\
\hline 1 e 3 & $\begin{array}{c}0,998 \\
(0,995-0,999)\end{array}$ & $<0,001$ & $\begin{array}{c}0,999 \\
(0,995-1,000)\end{array}$ & $<0,001$ \\
\hline 2 e 3 & $\begin{array}{c}0,992 \\
(0,980-0,997)\end{array}$ & $<0,01$ & $\begin{array}{c}0,996 \\
(0,979-0,999)\end{array}$ & $<0,01$ \\
\hline $\begin{array}{l}\text { Standard by US 2D } \\
\text { GS } \\
\text { Histogram }\end{array}$ & $\begin{array}{r}\text { ICC } \\
0,997(0,992 \\
0,998(0,992\end{array}$ & & $\begin{array}{l}\text { p-valc } \\
<0,00 \\
<0,00\end{array}$ & \\
\hline
\end{tabular}

Legends: Gray Scale (GS)

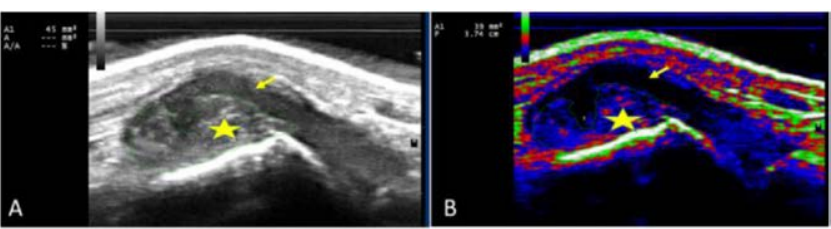

Figure 1. Patient with gout: A and B: Tophi area measures (star) in right metatarsos and efusion (arrow) by GS $\left(45 \mathrm{~mm}^{2}\right)$ and histogram $(39 \mathrm{~mm} 2)$, respectively. 